\title{
Trauma-Sensitive Practice for New Teacher Standards: Addressing the Epidemic of Our Times
}

\author{
Alexandra Fidyk \\ University of Alberta \\ Author's Note
}

This research, "Image, Body, \& Voice: Supporting Girls' Sense of Well-being," was funded by the Alberta Advisory Committee for Educational Studies (2016). The appropriate steps were taken to secure ethics approval via University of Alberta REB and the Cooperative Activities Program with the Edmonton Public School District, including a Police Information Check;

Contact the author by email at fidyk@ualberta.ca

\begin{abstract}
In response to provincial and national calls for whole school approaches, and in the hope to support new teacher competencies aimed at promoting mental health, this paper considers the changing dynamics within the current classroom through elements and implications of a participatory study conducted in an Alberta urban elementary school. Specifics from this research with young "girls," who engaged in ritual, ceremony, arts-integrated, contemplative, and somatic practices, target the on-going conversation on mental health and best practices in schools. Images of and from their life-size body maps are imbedded into the discussion, promoting the inclusion of body-centred, emotional, and imaginal dynamics to be integrated throughout teaching and learning. The discussion calls for the conscious shift of teachers, counselors, and leaders into more integral and ecological paradigms that understand health through the multifold relations with others and the environment. This argument is supported by trauma literature that calls for affective embodied experience, greater inclusion of right hemispheric activities, relational ethics, and teacher professional learning.
\end{abstract}

Keywords: trauma; mental health; whole school approaches; ritual; ceremony; contemplative, somatic, and arts-based methods; paradigm 


\section{Trauma-Sensitive Practice for New Teacher Standards: Addressing the Epidemic of Our Times}

Imagination and the body together are how children grow and heal.

$\sim$ Dennis McCarthy, 2007, "If you turned into a monster"

Feelings have their own kind of wisdom.

Nancy McWilliams, 2004, Psychoanalytic Psychotherapy: A Practitioner's Guide

\section{Mental Health and the Education Context}

Initiatives such as The Jack Project, " "Right By You," Dove Girls Self Esteem, Bell's "Let's Talk," and Teen Mental Health seek to improve the well-being of persons particularly youth in Canada (PMH; PHAC; $\underline{\text { WHO}}$ ). With suicide a leading cause of death among young Canadians, diverse initiatives and broad-sweeping mental health campaigns have been implemented (Navaneelan, n.d.). Statistics Canada (2012) reports one in five teens have expressed suicidal ideation during the year; 15-24 year olds had the highest rates of mood and identity disorders of all age groups; and about seven percent of them have identified with depression during the year (as compared to five percent of Canadians 25-65 years of age and two percent over 65 years). At higher risk for both depression and suicidal ideation are girls and young women. In fact, the rate of suicide has doubled for girls 10-14 years of age and has risen 50\% for those 15 19 years of age (Olson, n.d.). Aboriginal youth, who include First Nations people living on or off reserve, and Métis and Inuit peoples die by suicide at a higher rate than settler peoples, including multi-member or cluster suicide as witnessed in recent years. Many of the mental health issues faced by Indigenous populations are rooted in historical, inter- and transgenerational trauma, economic inequalities, homelessness, discrimination (e.g. justice system), and the effects of colonization-structures and beliefs upon which systems of education and health care have been founded and are maintained.

Add to these numbers the changing ethnocultural character of Canadian classrooms and we have a unique context for which many teachers have not been well prepared. Consider the findings of the Stats Canada 2011 National Household Survey (NHS): 1.4 million people had "an Aboriginal identity" and 1.16 million "foreign-born people immigrated in Canada between 2006 and 2011" ("Immigration and Ethnocultural Diversity in Canada"; "Aboriginal Peoples in Canada: First Nations, Métis, Inuit"). These statistics on mental health and community diversity paint a particular picture of classrooms wherein teachers are charged with the mandate to not only serve students well pedagogically but also attend them "compassionately" and responsibly regarding mental health - both of which require the care, attention, and availability befitting the charge in loco parentis (Alberta Education, 2017; ATA, n.d.; Edmonton Public Schools, n.d.)

In response to these statistics as well as increased cases of depression, self-harm, and bullying, public schools have become recognized as ideal and necessary places to address child and adolescent mental health (Wei, Kutcher, \& Leblanc, 2015; Wei, Kutcher, \& Szumilas, 2011). Recently published educational guidelines integrating systems of care (Government of Alberta, 2017) and new and emerging Programs of Study (Government of British Columbia, 2019-20; Government of Ontario, 2015) have intensified the need for "whole school 
approaches" (JCSH, 2008; McHale \& Maidrag, 2015). According to McHale and Maidrag (2015), whole school approaches integrate social and emotional well-being into all aspects of

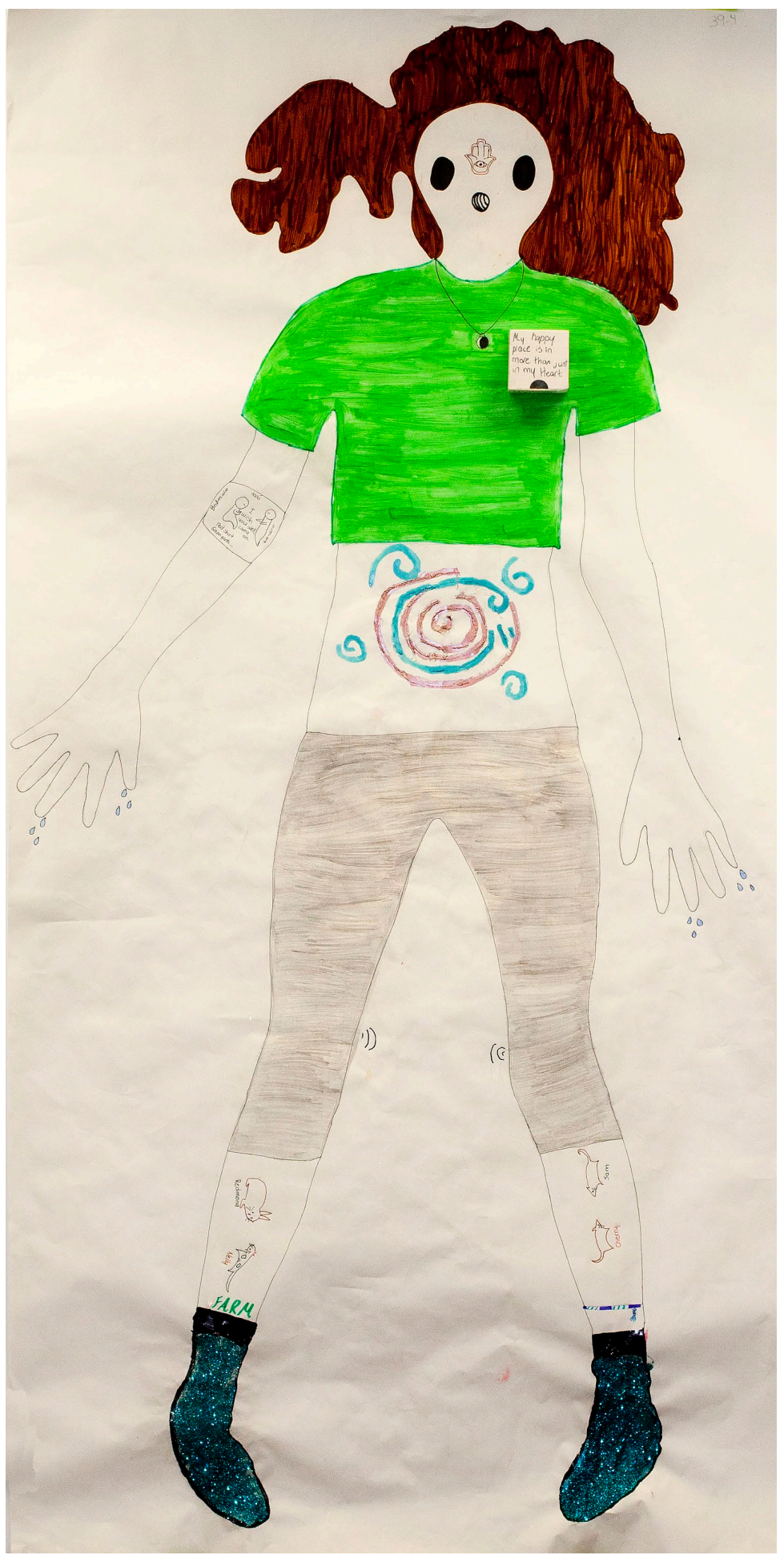

Figure 1. teaching and learning, promoting behavioural skills, and empathybased programs. Building upon Wells, Barlow, and Stewart-Brown (2003) who sought universal approaches to mental health promotion, effectiveness was found when interventions ran continuously for more than a year; they involved changes to the school climate; the changes were influence by students' voice (McHale \& Maidrag, 2015); and they were aimed at the promotion of mental health as opposed to the prevention of mental illness.

David Grauwiler (2018), executive director of the Alberta division of the Canadian Mental Health Association (CMHA), admits that the discussion of mental health in schools commonly shifts to "clinical interventions and the cohort of therapists, psychologists, and other helping professionals" ( $\mathrm{p}$. $20)$. While this type of work makes important contribution, "clinical supports and interventions" aid the "highest and most obvious needs" (Grauwiler, 2018, p. 20). The needs of many children and youth, with mental health problems who are not identified as vulnerable or in peril, will remain unmet and thus will not receive adequate support. Public Health Agency Canada reports that $10-20 \%$ of children and youth in Canada experience mental illness and only one in five children and youth who need mental health services receives them ( $\underline{\mathrm{CMHA}}, \mathrm{p}$. 9;). By 2020 the World Health

Organization ( $\underline{\mathrm{WHO}})$ predicts "depression will be the most common and disabling illness throughout the world, with early 
onset primarily in adolescence" and emerging adulthood (Brains Beyond Borders, n.d.). Unaddressed mental illness impacts the development of affect regulation, attention, cognition, perception, interpersonal relationships, and often plays a deterministic role in the emergence of later problems in social functioning, pathology, and disease (De Bellis, 2010).

\section{Traumatic Experience and its Traces}

Perhaps more alarmingly, trauma expert, Bessel van der Kolk (2014) argues, trauma is the "greatest threat to our national well-being" (p. 348). Trauma is an epidemic - not only among the world's low and middle-income countries but also throughout Canada at all socioeconomic levels. Indeed, the current climate might be called a worldwide "hidden epidemic" of trauma and fear (Lanius, Vermetten, \& Pain, 2010).

More explicitly, students in our schools have experienced traumatic events, including natural disasters; sudden or violent deaths of loved ones; violence at home, in the streets, community, or war; displacement and exile; via refugee or war-zone situations; terrorist incidents; as well as physical or sexual assault; motor vehicle accidents; medical/dental trauma (sudden illness/injury, emergency or medical procedure); interpersonal trauma (betrayal, abandonment, and abuse: emotional, physical and sexual); and neglect. Neglect is a more common form of trauma, yet it is not well understood. Despite child protective services' definition by law - "a significant omission in care by a caregiver, which causes or creates an imminent risk of serious physical or mental harm to a child" (De Bellis, 2010, p. 123) —neglect can occur at the hands of loving parents who are overworked and preoccupied. That is, with families decreasing in members, yet increasingly isolated and insular, parent(s)/carer(s) work longer work weeks, and in some cases suffer their own overwhelm and unattended trauma. In these situations, neglect can readily take form in the lack of supervision; failure to provide basic needs of nutrition, clothing, hygiene, and safety; and/or inadequate attention to a child's needs for affection, emotional support, or competence (De Bellis, 2010, p. 123). Trauma, neglect, and other early life stressors have adverse outcomes on cognitive and emotional development (Fisher \& Gunnar, 2010; van der Kolk \& d'Andrea, 2010). The number of students exposed to these kinds of encounters has increased substantially. It is unlikely that these numbers are going to diminish given world events and socio-political factors affecting current lifestyle choices.

Consistent across trauma research is the translation of trauma into explanatory terms. It is not the event that determines the traumatic injury (be it individual or collective) but the experience of overwhelm in relation to the event wherein there is a rupture to one's sense of subjectivity. This rupture leaves the individual's sense of self altered. Trauma describes any experience that causes a person unbearable psychic pain or anxiety. For an experience to be "unbearable" means that it overwhelms the usual defensive measures used to shield against outer forces (Kalsched, 1996, 2013). This description speaks to the red and black "explosion or eruption" and "churning" in both the head and the heart of this body map artist (see Figure 2). The colours red and black are the most commonly used across cultures to symbolize pain, hurt, injury, and suffering. Such experience can be personal, familial, cultural, ethnic, historical, collective - national, religious, geographic - (Erickson, 1976), intergenerational, and transgenerational (Wirtz, 2014, 2015; Wolynn, 2016, Yehuda, 2002). 


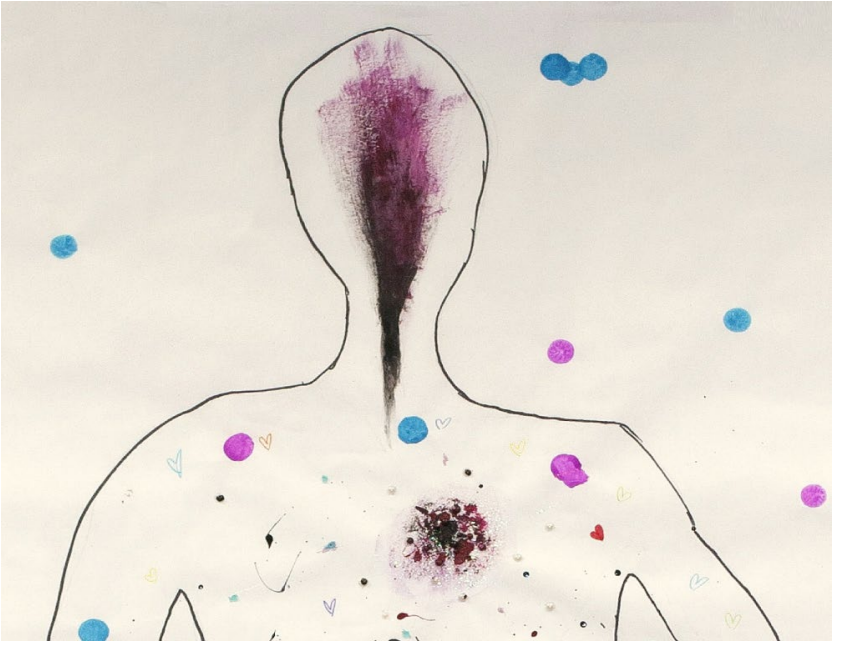

Figure 2.
For this artist (Figure 2), the "emptiness" of her body map in comparison to the maps of the other participants, led her, during the last moments, to "fill" both her body and the space around it with fushia and turquoise Bingo dabber marks and small, colourful circles and hearts. Besides a stage with half-open curtains in her solar plexus, which symbolized zir safe place, these two symbols spoke volumes as they were what she felt. In total, these were the only three inkings on her body map until the reactive "filling-in."

In an aptly titled chapter, "Life after "death"," Lombardi and Gordon (2014) offer a tangible description of what happens in an individual who experiences trauma: "At its core," they begin, trauma is "a moment that tears into the course of normative living, altering the very bounds of identity" (p. 172). They add, "Trauma breaks the frame of contextual experience and the capacity to continue narrative accounts of personal history"- a rendering which accounts for the fragmentation and dissociation that ensues. Understanding trauma as a "break, a rupture, a tear, a fracturing in the psyche," wherein "trauma atomizes one's sense of subjectivity, disturbing psychic boundaries, neurological encoding, and symbolic functioning" accounts further for breakdown in language, understanding, even the body (Lombardi \& Gordon, 2014, p. 172). This shattering interferes with relation to others; it undermines belief systems that give meaning to experience; and it violates faith in a natural or divine order, casting the individual into a state of existential crisis (Herman, 2015 p. 51). If we consider the massive impact of trauma upon people - that is, upon students, teachers, and other school members - the very way we come together requires reconfiguration. If the sense of self as a whole person, along with a sense of belonging, and access to safe and trusting relations are threatened via a traumatic injury, then what we do, how we do it, and why we do it, requires radical reimagining.

\section{Collective Experience of Trauma}

Trauma can be experienced collectively as well as individually, thus becoming complex trauma. According to the 2003 annual report of the Aboriginal Healing Foundation, "Thousands of former students have come forward to reveal that physical, emotional, and sexual abuse was rampant in the school system and that little was done to stop it, to punish the abusers, or to improve conditions" (p. 16). "The fact that there were no repercussions for perpetrators of institutional abuse within this system," writes Renee Linklater (2014), author of Decolonizing Trauma Work "produced serious consequences for children as they learned to devalue their safety and personal boundaries and to become accustomed to living within abusive environments" (p. 43). Without any acknowledgement or responsibility taken by those within the system, it made treatment unacceptable. Additionally damaging, abusers received salaries and administrative support while committing violations (Linklater, 2014). Trauma 
must be taken up systematically-discussed or pursued in public, thereby making its study legitimate and political. In so doing, it too resists the "social processes of silencing and denial" (Herman, 2015, p. 9). However, individuals within organizations, systems, and societal structures must hold "traumatic reality in consciousness" so to affirm and protect those who have suffered trauma, thus joining "victim" and "witness" in a common alliance (Herman, 2015 , p. 9). Understood in this way, the report brings painful realities to light, ones which must be addressed by raising awareness, transforming attitudes, and changing behaviour of adults in schools who work with Aboriginal children and youth as well as newcomer, vulnerable, and settler populations. While educators need to become more cognizant of present trauma-the ways it presents and supportive attitudes and actions in response-we must also be intentional about past traumas, including inter- and trans-generational trauma among Indigenous peoples (see Gaywish \& Mordoch, 2018).

Critically relevant to Indigenous and settler relations is the fact that unbearable and intolerable events refuse to be buried. In her potent historical analysis, Trauma and Recovery, Judith Herman (2015) argues, "Remembering and telling the truth about them are prerequisites both for the restoration of the social order and for the healing of individuals, families, and collectives. ...The conflict between the will to deny and the will to proclaim [atrocities] is the central dialectic of psychological trauma" (p. 1). Without a witness, and a means to express and release the event, it often manifests as a symptom, disturbing multiple areas of functioning - educational, family, health, and vocational. Traumatic experiences leave traces, whether large scale - on our pasts/histories, societies/cultures, systems/structures - or close to home, on our families, our students/patients/clients, and our communities, with dark effects imperceptibly passed down through generations (see Wolynn, 2016 and Yehuda, 2002, regarding inherited family trauma). They too leave traces on our minds and emotionsimpacting our learning and memory-on our capacity for joy and intimacy, even on our biology and immune systems.

\section{New Standards, New Learning, New Paradigms}

Because educators and staff members in schools today are expected to undergo professional learning to acquire skills that support child and youth mental health (Kutcher, Wei, McLuckie, $\&$ Bullock, 2013), the response requires the development of mental health resources, supports, and training for them (Wei et al., 2011). Revision to the Alberta School Act has introduced new criteria to the Teacher Quality Standards (TQS) to ensure that teachers can facilitate "response to the emotional and mental health needs of students" (Alberta Education, 2018, p. 6); demonstrate "empathy and genuine caring for others"; and support "inclusive, welcoming, caring, respectful and safe learning environments" (p. 4). The new standards will apply to teacher certification, professional development, supervision, and evaluation commencing fall 2019 so many teachers require supplementary learning to meet this mandate within the context of diverse school communities (Alberta Education, 2018).

With increasing diversification in schools, the design and implementation of mental health models cannot afford to overlook the cultural forces biasing Western conceptions of healthy functioning, and in kind, practices and systems that support "health" (LeBlanc, Talbot, \& Craig, 2005; Unger, 2005; Unger et al., 2007). The allopathic medical model, for example, is based on disease hence illness, not wellness. Allopathy does not aim for optimal health, enhancement, or maintenance of wellness, nor prevention of illness. Too, it focuses on the 
individual and not families or communities. In contrast, "The Mental Health Commission of Canada recommends that mental health promotion and prevention initiatives must engage communities"(Brains Without Borders, "About") — a call that is echoed by other organizations whose mission is to promote mental health(see Brains Without Borders, "About" . Similarly, psychiatry, a field that pathologizes Indigenous peoples' experiences, considered but later rejected the DSM-category for "residential school syndrome" (Chrisjohn \& Sherry, 2006, cited in Linklater, 2014, p. 21). Its reliance upon DSM diagnoses adds to the stigmatization around mental health, and it "pathologizes purposeful and valuable coping strategies commonly used by people who are traumatized" (Burstow, 2005, p. 429). Helping professionals must be cautious though about rejecting psychiatric diagnoses because "doing so jeopardizes insurance coverage and compensation claims" (Burstow, 2003; 2005 cited in Linklater, 2014, p. 22) that aim to aid mental health. As such, the structures central to these systems put many in a double bind.

When we shift our frames of reference to paradigms and perspectives of health and healing that focus on "restoring balance to the self through relationship with other and the environment" (Stewart, 2007, p. 190) potentialities emerge. Health and healing, as found in Indigenous, traditional, and integral worldviews, mean mind, body, soul (personal), and spirit (creative principle). Here, not only are relationships and interconnections within a larger web of life throughout time primary, but also body is the core of inter-, intra-, and trans-personal relations and epistemologies associated with well-being and wholeness. One valuable example of this is the Cree/Algonquin/Plains Wellness-Medicine Wheel with its four-direction gestalt (also see Gaywish \& Mordoch, 2018; Linklater, 2014). We must become receptive to other paradigms in order to support whole school approaches, especially ones that offer worldviews beyond both modernity and post-modernity. Neither of these historical paradigms values the predominance of relations - the energetic, subtle, and concrete-and similarly, they both ignore the ancestors, collective knowing, tradition, the unconscious, and the spiritual. To begin to imagine other images of wellness, ones that see our selves as interdependent with sky, place, and the particularities of place, are favourable because they open us to both the always already

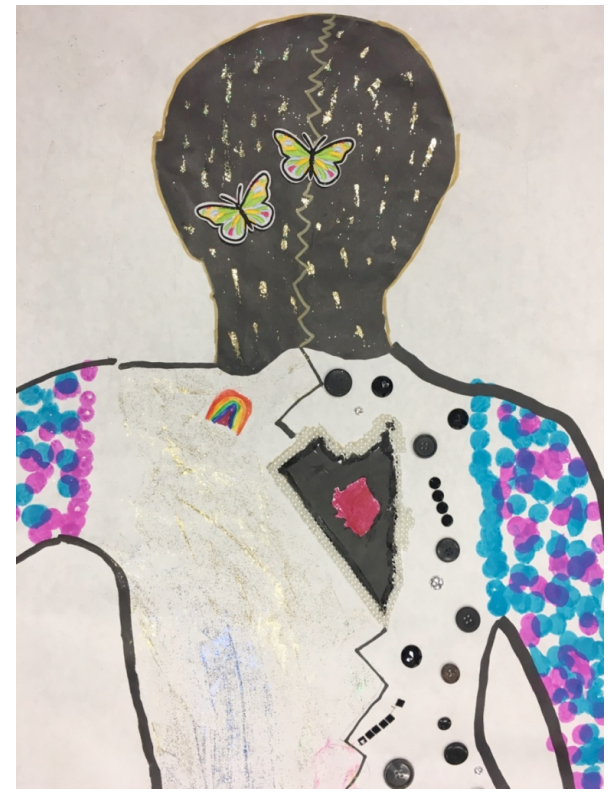

Figure 3 and the not-yet. This ontological and so corporeal turn cannot be bypassed. Our well-being, both individually and collectively, depends on innumerable relationships that include animals, air, gardens, vacant lots, the elderly, and community members engaged in our schools but also at all levels of community.

\section{Transdisciplinary Praxis and Somatic Awareness}

Affected by these mental health realities and attendant to the emergent need to provide intercultural mental health perspectives, resources, and methods that work across cultures, I conducted a participatory poetic inquiry with eight Grade 6 girls, aged 10-11. We were guided by the following question: In what ways might girls' experiences with art-integrated activities and body-centering techniques inform educators about pedagogical practice and mental health interventions? 
The study unfolded through an animated paradigm, a worldview that supports the imaginal and poetic basis of consciousness as well as an ecological sense of being. Its ontology reflects a worldview that includes and values images, intuition, feeling, the unconscious, transpersonal, transgenerational, transgender, and emergent dimensions (Fidyk, 2013, 2017, 2019). It calls forth practices and knowing inherent to pre-modernity, traditional, and Indigenous peoples: ritual, ceremony, expressive movement - such as drumming, dancing, and chanting - community healing, dreams, visions, and the ancestors to name a few.

Methods (moves) were carefully chosen and layered wherein a transdisciplinary praxis emerged. Arts-integrated practices of imagining, colouring, tracing, painting, and playing (Knowles \& Cole, 2008; McNiff, 2013; van der Kolk, 2014); and body-centered techniques, such as breathing, grounding, visualizing, and moving (Rosenberg \& Kitaen-Morse, 1996; Rosenberg, Rand, \& Asay, 1985) were woven into practices inherent to integrated body psychodynamics: attunement, containment, boundaries, breath, and agency; and trauma studies: titration, pedulation, resonance, somatic awareness, and somatic empathy. Understanding informed by analytical psychology was both the backdrop to these moves and the guide for inclusion of active imagination and symbol amplification-so to encourage cultural inclusivity and to honour difference via body, gender, language, and spirituality (Levine, 2005/2008, 2015; Manwell et al., 2015; van der Kolk, 2014).

Though named methods, within this paradigm, each cluster is in actuality ontological. That is, each is a way of being - although not recognized as such by dominant perspectives within educational research and current Western systems (education, justice, medicine, etc.). Each move while embodied or practiced was theoretically informed. As a guiding gestalt, we explored the relationship between "girls" images of self as depicted through their relationship to their bodies and to their sense of well-being through stories "written on the body" (Devine, 2008; Gastaldo, Magalhaes, Carrasco, \& Davy, 2012; Karlsson, 2012; MacGregor, 2009; Wienand, 2006;). That is, their personal narratives, their remembrance re-imagined, became symbolic tats inked upon life-size body maps.

Ontologically shaped, this positioning reforms the guiding ethics not only in conducting research ${ }^{2}$ but also in opening up relations within the school community and beyond. Of import are the ethics of relationality (with each other, our bodies, space, art, spirit/s, energy, and families), and "relational accountability" (requiring reciprocal and respectful relationships), thereby reflecting inter-being, empathy, humility, kinship, and care-qualities inherent to a sense of belonging to a much larger cosmos (Wilson, 2008). Such a paradigmatic shift welcomes diversity in culture, language, tradition, and science (Cajete, 2000), allowing greater complexity and potentiality in understanding and practice. It then invites increased inclusivity of students and families within our schools and communities.

Faced with the facts that girls attempt suicide and self-harm at higher rates than boys, as well as have greater percentages of incidents of trauma, girls are at higher risk for mental illness and death (Statistics Canada, 2012). Add to this the pervasive quality of social media and media culture that targets the lives of youth, where dangerous and unrealistic cultural ideals of body and beauty distort a healthy sense of well-being (Korr, 2015"Girls Body Image"; Westerberg-Jacobson, Edlund, \& Ghaderi, 2010). For example, more than 50\% of girls age six to eight years of age report their ideal body is thinner than their current body, and " $87 \%$ of female characters age $10-17$ on the most popular kids' TV shows are below average in 


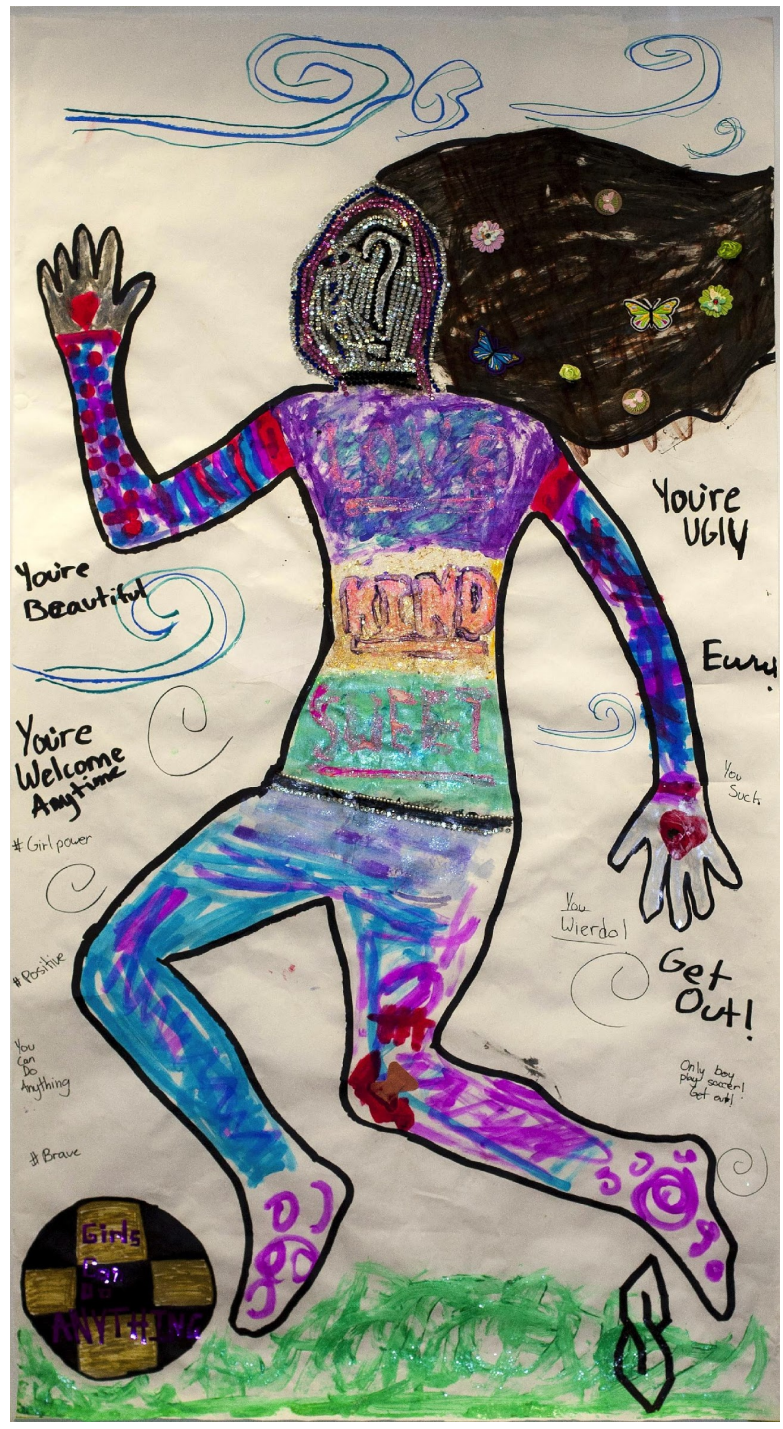

Figure 4. weight" (Common Sense Media, "5 Ways to Promote a Healthy Body Image for Girls,"n.d.). Likewise, the harmful socializing mantra: "Be nice, sweet, and kind"-implies obedience and silence and thus lack of agency and voice. To the point, this artist (Figure 4) wrote on her torso in capital letters: "Love, Kind, Sweet." Where such socialization occurs, they most likely have not been taught that their boundaries matter, that their interiority matters - they matter. To learn that one's bodily feelings and sensations communicate from deeper levels is to trust not only one's body - and what it says - but also what one's body feels in relation to space and time and other. When girls (and in general children/youth) discover, they have voice, even if it is expressed as conscious silence, action, or art-as this young artist came to do-it can be used to protect themselves and what they love. Too often girls are socialized to consider others first, often at the expense of their own desires and well-being. Regardless of culture, overriding one's own safety impacts one's sense of trust and security. Research has shown that having a poor self-image is highly related to low self-esteem, affecting mental health, and in turn, learning, and social functioning (Duncan, Duncan, \& Schofield, 2011).

Aware that any healthy changes that unfolded through the girls' participation needed to be supported outside of our meetings, their homeroom teachers were formally invited ${ }^{3}$ to meet with me at the onset, mid-way, and at the end of the study to discuss their awareness of and attention to the body and the arts in learning. I was curious about their interest in reflexive practice, along with professional learning via curricular and pedagogic development regarding ways to better understand emotional and mental health needs. One of the teachers shared examples of ways students were engaged with movement and breathing practices during class. The other spoke of observations and concerns about the girl-participants but seemed reluctant to engage in real inquiry regarding pedagogic practice. It was difficult to direct their attention away from the girls and onto their teaching.

For mental health to be addressed by teachers, counsellors, and leaders, a shift in understanding human physiology is needed - that is, "what the body remembers" (Singh Baldwin, 1999); what the body tells us; and the ways it tells us. For example, in the pilot study and two similar studies conducted at three different school sites, with "girls" of relatively the same age (Grades 6 to 8), they consistently, and alarmingly did not give themselves anatomical 


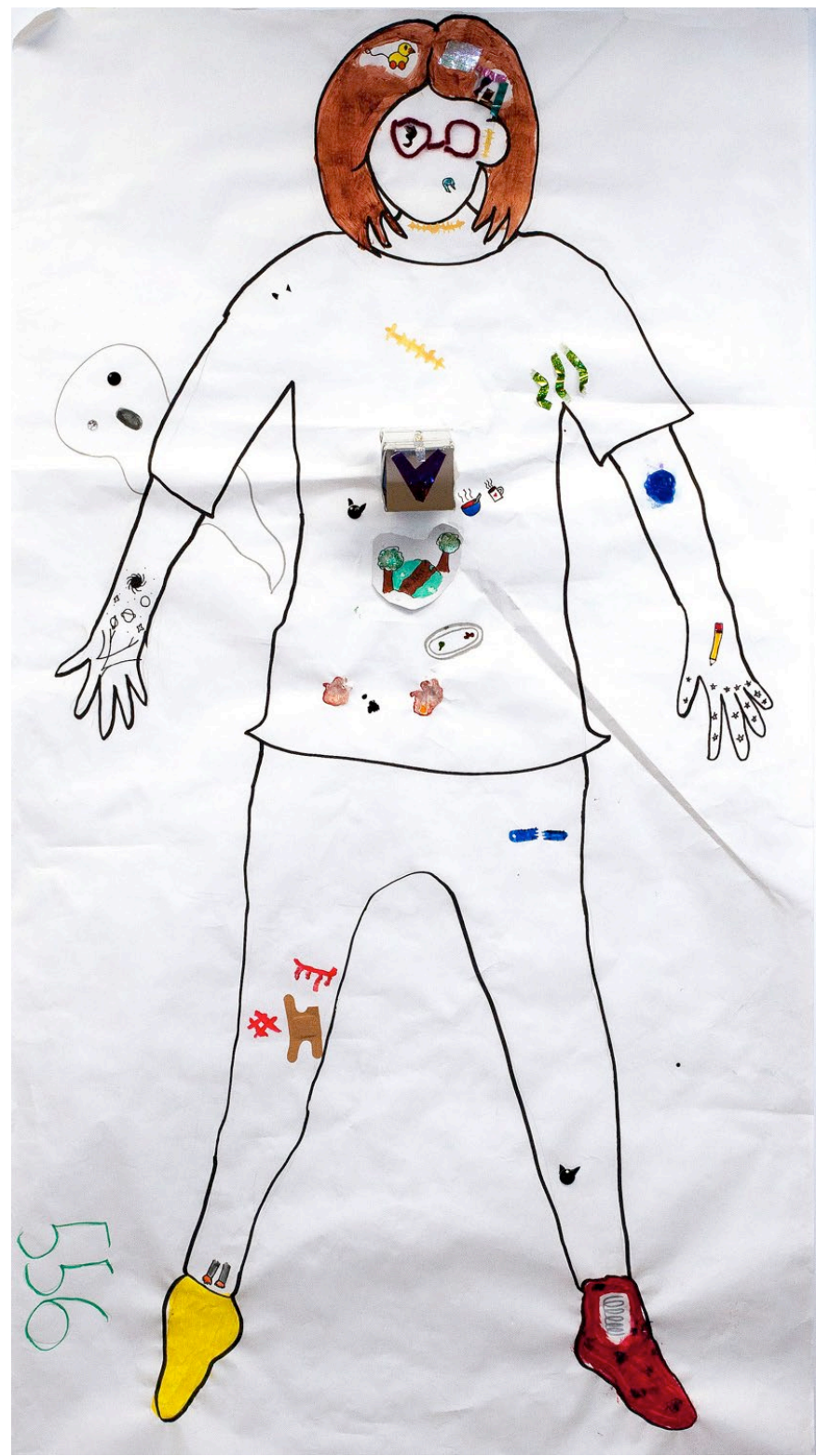

Figure 5. faces. While this body artist (see Figure 5) gave herself glasses, she has no eyes. Noticeably, there are no mouths, except for an ambiguous circle where the nose and mouth might be on the first body map included. However, based on the symbolism across the groups, it seems to be an open mouth with bars encaging it- just as other artists have drawn a patch or label with "Sh" on it, stitches sewn across an absent mouth, or nothing. Physiology is crucial-to everything that happens in schools (learning, socialization, physical activities, music, drama, etc.) and to the quality of our lives. Studying the physical features given and not given to themselves speaks volumes of their embodied experience whether conscious or not of it. In order to embrace $a$ shift to and for the body, that is - to and for health and wholeness - the mind body split, which privileges the former, must be discarded. Experience confirms the brain-mind/body are one and function as a unity. Nevertheless, the allopathic medical model and numerous academic disciplines, all of which influence education, value the thinking functionlogos, reason, and abstraction-to our detriment. Taken further, most assessment privileges this function and worse, negates, even punishes use of the feeling function, ${ }^{4}$ and its kin-emotions, affect, and bodily feeling. For any

serious address of trauma, however, the body's wisdom must be rediscovered; its finitude not resented; its limitations not abhorred; its thought not disembodied. Teachers, counsellors, and leaders engaged in campaigns that seek to support child and youth mental health must then expect to be changed in their practice. For if they are not embodied, that is, in relation to their interiority, they cannot know when the child is neither, nor can they know how to respond appropriately (i.e. emotional regulation).

\section{Ceremony and Social Engagement}

In addition to being-in-the-body, creating and maintaining interpersonal and intrapsychic safety, security, and boundaries are required for teachers to intentionally attune to students and their needs. Each afternoon when the girl-participants gathered for the study, I had covered the 
windows for privacy and rearranged the library to open spaces yet create boundaries for containment. I laid out art-making supplies, prepared drinks and snacks, and placed personally designated yoga mats in a circle - one for each of us. By the third meeting, when the girls came through the library doors, marked "Closed," they literally walk-ran toward the circle. With shoes and backpacks tossed aside, this ritual beginning built the energy of a ceremony. Our easy and comfortable engagement quickly created a palpable transcorporeal field, which extended safety, encouraged trust, and offered the potential to convert and regulate difficult arousal states, ${ }^{5}$ such as anxiety and fear, into relational connection. ${ }^{6}$

All cultures celebrate essential elements of life in different forms of ceremony. Trauma expert, Sharon Stanley (2016) in her extensive experience and research with First Nations Peoples, describes a ceremony as involving encounters that "contain and hold the disturbed energy of trauma along with the natural healing forces of life" (p. 77). "In many ways," she continues, "the encounters of the new paradigm in Western healing practices, right-brain-toright-brain affective embodied experiences that Schore (2012) advocates, are ceremonies that bring essential elements together for healing trauma" (Stanley, 2016, p. 77). Ceremony can take the form of a "contained intersubjective dialogue between two people of a group"; "a meditation, or the experience of sharing and embodying imagination and dreams, dancing, music, or other expressive forms" (Stanley, 2016, p. 77). The elements that constitute a ceremony "include embodied intersubjective relationships, the rituals of sacred, uninterrupted time, the development of bodily based rhythm and movement, and somatic relational exploration of internal and environmental influences on human experience" (Stanley, 2016, p. 77). Social engagement, stimulated by the ventral vagal circuit, is continually strengthened to be the primary form of defense in traumatic moments rather than the isolation that typically comes with a sympathetic reaction (Rosenberg, 2017). So the "quiet kids" on the margins of the classroom, the ones alone at break/recess or "resisting group work," may well be caught in a self-preservation defense; thus, their behaviour is not who they are, their personality, but rather unconscious action performed for survival. Ceremonies are valuable methods because they have the power to "bring the fragmented elements of dissociative experiences together in an alive and pulsing container for acknowledgement, conversion, metabolism, and transformation of lived experience" (Stanley, 2016, p. 78).

In developing a ceremonial encounter to support well-being, a clear and caring intention for the participants and me was required. An intention honours the unique transsubjective and transcorporeal relationship in the moment and gives careful body-based attention to space, pace, time, energy flow, and connection among participants and the environment-whereby an "ecology of relationship" (Hockley, 2018) constellates. Then follows, the greeting, a "moment of meeting," that fertilizes the "right conditions" of the encounter and the potential conversion from sympathetic arousal ${ }^{7}$ to social engagement-a relaxed, parasympathetic response (Stanley, 2016, p. 78). ${ }^{8}$ The greeting is mindful, involving a respectful presence and welcome; a moment of soft eyes, naming the other-Ms. J, Ms. M, Ms. $\mathrm{S}$ - and physical guidance with gesture and movement into the space where something can happen. Like a ceremonial dance, this embodied greeting set the theme and ethos of relational caring and respect for the girls as persons (Stanley, 2016).

After the intention and invitation, we engaged in breathing techniques. We charged our bodies and we calmed them. We grounded through eye contact and touch, and we expanded our body-containers by sustaining an energetic charge. They loved "grounding"-techniques 
that drew their awareness into their bodies, such as rocking on their sit bones to feel the pressure of their bums against the mat and floor; the temperature of another's open palms in arms-forward-warrior-pose, or naming things by inviting the eyes (not "I") to scan the environment for what grabs them (i.e. green chair). Despite their initial discomfort with the breathing practices, when interviewed, they all reported using them during sports, at home, and in class, especially when angry, tired, or bored.

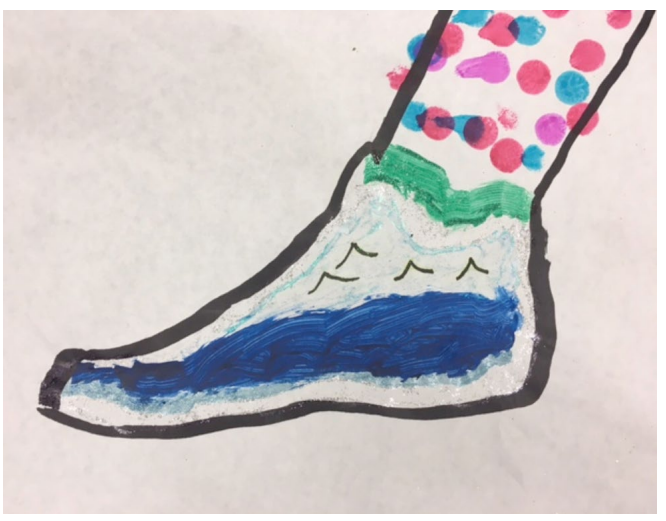

Figure 6.

We participated in visualizations and body scans. The first visualization was the most powerful and central to the work. They were invited to recall a memory or to imagine a place that made or would make them feel safe and content. They amplified the memory or imagining through detail-its colour, texture, size, shape, and temperature. Then they were invited to feel into their bodies and ask, "where does this symbol want to dwell-secure and readily available?" A Newfoundland beach scene from family vacations, for example, was painted on this artist's feet, complete with seagulls and glittering sand (Figure 6). This home base began their body narratives and offered a residence rooted within, protected and protective, for whenever needed.

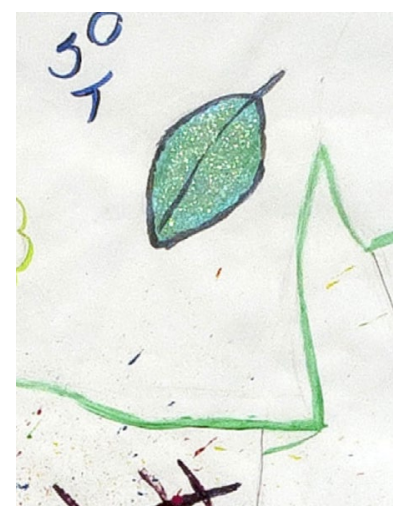

Figure 7.

Equally important to these practices was for the participants to "safely experience their sensations and emotions" (van der Kolk, 2014, p. 215). This awareness was encouraged through internal scanning to notice sensations, emotions, and/or lack thereof in the body, such as tingles in one's heart for the love of nature. This participant-artist (Figure 7) asked me if I had additional hues of the green colour palette - sea, jade, Persian, and emerald - as she had an unwavering sense of the green that was her heart. Guided intuitively and somatically, the birth of this leaf took an entire session (1.5 hours), with multiple layers of paint and sparkle lovingly applied.

Schooling commits violence against children and youth when they ignore their bodies. Prolonged periods of time when children are required to sit still, be quiet, and follow instructions (without engagement) deadens their brains-minds and bodies quite literally. As a result, many have learned to dissociate, split out, or cut off from their bodies. The integration of contemplative practices sought to develop and support the girls' sense of self, as well as to teach them skills needed to communicate inner affective states and an attitude that honours their interiority. "Engaging the self-observing, body-based self system, which speaks through sensations, tone of voice, and body tensions" (van der Kolk, 2014, p. 238) aids to establish a relationship with an inner presence, which in turn, provides a sense of safety, which can be accessed when needed. Teachers can integrate such awareness and subsequent activities daily at any level of learning across curricula. 


\section{Sharing Circles, Boundaries, and Feelings}

Sharing circles, like talking circles, while not a new idea for Indigenous people and Indigenist research, are newly being accepted as a research method in social science and educational research. As the beginning and closing ritual to each research afternoon, sharing circles were used to develop a community of trust and to establish a new ethos, "where each person had the opportunity to take an uninterrupted turn" while speaking to the topic, where each had an equal chance to speak and be heard (Wilson, 2008, p. 41). The yoga mats, deemed sacred space, provided a concrete visual for each girl to come into relationship with her own energetic space, body, and that of other. They also aided to demonstrate the importance of boundariesphysical, emotional, and intimate - wherein paradoxically a "sense of interconnectivity grows" (Stanley, 2016, p. 79). We can only feel safe if we know that others will respect our boundaries - not moving in too close or too far away; hence, the development of character style based on our early experiences of inundation and abandonment (Rosenberg, Rand, \& Asay, 1985). Boundaries also reflect the capacity to build, sustain, and discharge energy. Thus, respect of this space was paramount and the girls took to the idea readily. ${ }^{9}$ If we do not have boundaries, we protect ourselves through other means, that is, defenses, such as:

withdrawal, control, side-tracking, creating rules, scapegoating, humour, sex, rationalizing, intellectualizing, name calling, perfectionism, black-white thinking, threats, gas-lighting, coldness, sweetness, excessive concern for the other-all are handy ways to avoid feeling and to avoid communication. The healthy alternative is to state valid feelings. (Katherine, 1999, p.115)

While sharing authentic feelings may sound simple, bodily sensations and emotions are not an overt part of curricula or learning, and so, unspoken, they lose value, become diminished, concealed even forgotten. In fact, most would not recognize them as vital to learning! For girls, in particular, this exclusion and devaluation is a form of neglect to their growing sense of self, in relation to their own bodies and awareness, and to their interrelations with others. Once stated, however, someone must be present to hear, to see, and to reflect back what was heard and seen. Such reflection can occur during check-ins and outs, in journal writing, even group work. Many teachers, especially in secondary schools, are not comfortable with reference to the inner lives of their students or even of themselves - their own bodies. But it is the fragmented self who is "at home in a disembodied state and content to rely on knowledge garnered through logic and reason .... When we divide ourselves into parts we lose the connection to the whole of who we are and our inner connection" (Mortimore, 2013, cited in Stanley, 2016, p. 65).

As long as emotions, feelings, and bodies are feared, responses to mental health needs will be grossly limited. Sensations are the touchstone to well-being. In truth, even the language of sensations - tingly, frozen, whirling, tight-has been forgotten. The question: What sensations do you notice in your body? usually requires several reiterations including reframing before a sensation is reported. The common answer is either an emotion or a narrative that becomes rationalization. For many with trauma, their sensory world is off limits because it can be frightening and painful to feel. In order to change, we need to open ourselves to our inner experience. Body awareness puts us in touch with our inner world - the transitory nature of our feelings, emotions, and perceptions. After all, emotions are inseparable from the body in which they are felt. They are the basis of our engagement with the world. Stanley 
(2016) agrees: it is through "regulation of intense emotions" that we build resilience (p. 53). Since "emotional regulation is the critical issue in managing the effects of trauma and neglect, it would make an enormous difference if teachers, ... and mental health professionals were thoroughly schooled [in such] techniques" (van der Kolk, 2014, p. 207).

When we learn to co-regulate and eventually self-regulate intense emotions, we can stop the repetition of old patterns. With practice, we can prolong the duration of time between sensation and impulse so we are no longer hijacked by the initial trauma response (fight, flight, freeze, and collapse). Because "the right hemisphere continues its growth over the life span, thereby allowing for [affective embodied]-induced plasticity in the system" (Schore, 2012, p. 107), we can gain reprieve from injurious memories frozen within our cells - potentially preserved lifelong. Emotional regulation techniques are critical for managing the effects of trauma and neglect - to say nothing of the anxiety, overwhelm, behavioural challenges, even depression, that are experienced by many on a daily basis at school. Various practices can be integrated into lessons and activities throughout a school day. To skillfully do so can restore an earned secure attachment, which requires an intersubjective relationship - two or more persons (pet or imaginal caring creature such as Szen, the caribou, in Frozen) both sensed and known to each other to the end that they can effectively co-regulate and make sense out of lived experience. This reattachment can occur even when reading an affective piece of literature aloud, followed by reflective discussion. What this shift asks of teachers is to develop self-care practices that restore their embodiment, thus presence, and an increasing capacity to sit in the unknown, uncertain, and uncomfortable.

\section{Imagination, Play, and Creativity}

"The greatest hope for traumatized, abused, and neglected children," offers van der Kolk (2014), "is to receive a good education in schools where they are seen and known, where they learn to regulate themselves, and where they can develop a sense of agency" (p. 351). To be seen and known requires being in relationship. It requires the other to be present, capable of attunement and the ability to separate what is personal and what is not, so to actually see, and see without judgement. ${ }^{10}$ When a child does not have to defend or protect, she can genuinely imagine, play, and create. It is out of this state, psychoanalyst W. D. Winnicott (1971) claimed, "a creative reaching-out can take place" (p. 75). The "creative reaching-out" of playing, which he understood as the search for self-creative activity as the search for self-contributes to an integrated sense of self when another reflects back that play. For Winnicott (1971), play, reflected back by a friend or teacher, is the creation and validation of a meaningful relationship with the world. When awareness of one's inner reality, and elements of external reality unite in a safe and trustworthy environment, with another who "sees you"- "the individual can come together and exist as a unit [that is, as a whole], not as a defense against anxiety but as an expression of I AM, I am alive, I am myself. From this position everything is creative" (Winnicott, 1971, p. 76).

While this may sound basic, doable, teachers have become overloaded, even overwhelmed by large class enrollment, diverse individual needs, and accountability to student performance on standardized exams. Teachers' capacities to be calm, embodied, and present are among, if not the most crucial factors to support students' sense of safety. When children cannot find the safety and care needed for healthy attachment and development in their own homes, schools then become sites of hope where such development might occur. Too often, 
disturbing behaviour, truancy, and rebellion are interpreted as a threat to order and classroom management, whereby, it becomes personal for teachers, rather than as frustrated attempts to communicate distress and misguided efforts for self-preservation.

"More than anything else," van der Kolk (2014) stresses, "feeling safe with other people defines mental health"; safe relationships are "fundamental to meaningful and satisfying lives" (p. 352). As educators, we are now obligated to "foster reciprocity" (not equal but mutual) (van der Kolk, 2014, p. 352). That is, to hear and be heard-sincerely, to see and be seen-honestly. Addressing the effects of trauma in children and youth begins with fostering safety, establishing predictability (not stifling repetition), and ensuring teachers' capacities to see, hear, and know children/youth. ${ }^{11}$ Studies repeatedly demonstrate that "having a good support network constitutes the single most powerful protection against becoming traumatized" (van der Kolk, 2014, p. 210). In the same manner, "traumatized people recover in the context of relationships" (van der Kolk, 2014, p. 210). "Not being seen, not being known, and having nowhere to turn to feel safe is devastating at any age, but it is particularly destructive for young children, who are still trying to find their place in the world" (van der Kolk, 2014, p. 88). Only in the last 20 years has the extent of the "problem of developmentally injured human beings begun to be recognized and understood" (Felitti, 2010, p. xiii). The limits of that understanding and the resistance to it have reached critical levels - "causing a serious and widespread threat to health and well-being" (Felitti, 2010, p. xiii). We can look to Adverse Childhood Experiences (ACE) studies for striking results that confirm the relationship of childhood trauma, abuse, and "household dysfunction" to multiple "health risk factors, adult disease, and many of the leading causes of death in adults" (Felitti et al., 1998, p. 245).

\section{Witnessing, Imagination, and Feeling-Felt}

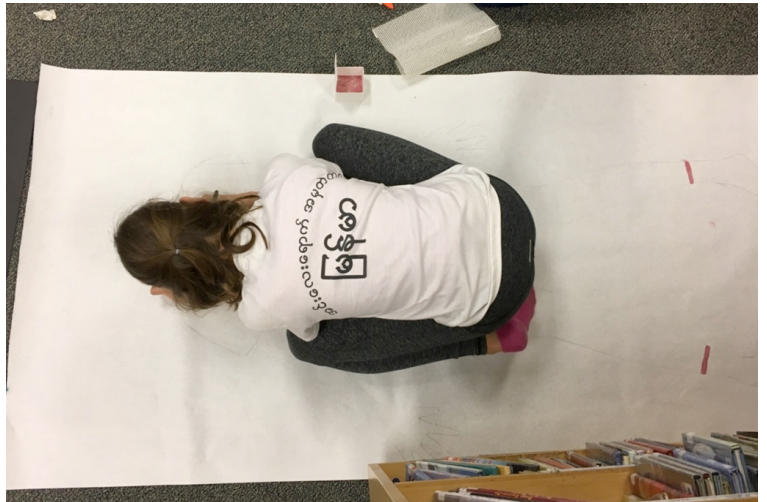

Figure 8.

With safety established among the participants, we moved from our opening ritual of sitting circle, to where the girls worked comfortably and silently on the floor, engaged in various creative processes. The body-centered symbolic process lasted 60-90 minutes. For six arts-integrated sessions, sensations felt via body scans directed what symbols were added to their body maps each week. Some worked sitting to the side of their maps, leaning in, while others sat upon their bodies working intimately through constant touch (Figure 8). In this way, hour after hour, day-by-day, they noticed themselves: they noticed their bodies; they noticed what they felt; and they noticed where they felt it. They learned to attune physically with their sensations, feelings, and their experiences so to voice the way they individually perceived their bodies, their lives - their stories.

To amplify with increased detail what they noticed aided to increase consciousness about their inner worlds. When we pay focused attention to our bodily sensations, we can recognize the ebb and flow of our emotions and, with that, increase our control over them. For van der Kolk (2014), "the core of recovery is self-awareness . . . . Body awareness puts us in touch with our inner world ... [without such awareness and the ability] to observe the 
interplay between our thoughts and our physical sensations" (pp. 208-209) there can be no healing. Taken further, our inner worlds in meaningful relation to our outer worlds is what moves us toward reflective self-conscious awareness of our dynamic interconnected web of life and thus to empathy and reciprocity.

In response to the particularities shared during this research, I was compelled to bear witness to the girls' lives. As witness - I listened without judgement, was open and curious. Witnessing says that your suffering matters. Indeed, this vital element permitted the felt experience needed for the participants to feel felt and consequently, seen, heard, and accepted "just as I am." The experience of being oneself, of being with oneself, without critique, inundation, abandonment, or expectation, grants us a sense of connection and joy-as revealed when we said goodbye at the end of the interviews and several girls (and I) wept openly.

Within trauma studies, imagination has been deemed "absolutely critical to the quality of our lives" (van der Kolk, 2014, p. 17). Learning how to integrate imagination, that is, divergent, convergent, and evaluative opportunities, across and through the subject-areas becomes fundamental to pedagogy. Connecting the emotional, symbolic, and imaginal domains with learning develops the right hemisphere. The right hemisphere knows through contact with direct phenomena of lived experience and is interested in sensations, movements, emotions, and images that spontaneously emerge when we process internal and external events. The left hemisphere, the favoured side within formal systems of learning, is not interested in the body as the "intersection between ourselves and the world at large" (McGilchrist, 2009, p. 67). And worse, it can fragment body-based experiences from mental activity. When living in "chronic disembodied states," people discount, even neglect, the communications of their sensations and emotions, creating idealized alternate "states of being that are out of touch with the reality of their lived experience" (Stanley, 2016, p. 65).

For trauma experts, van der Kolk (2014), Levine (2015), and Stanley (2016), we are moved, changed, and transformed as we surrender our abstract, logical, and sequential ways of knowing to the bodily-centred, emotional, and imaginal dynamics of our lived experience (Sieff, 2015). Affective embodied experience has the power to spontaneously shift traumabased neurological states and stimulate an intrinsic vitality to transform brain-mind/body patterns that formed through traumatic experiences (van der Kolk, 2014). Educators must have access to new understanding and professional learning opportunities whereby they too can experience relational and body-centered approaches so to invite the body and the arts into their classroom practice (pedagogical, ethical, and relational). Such development will, in hand, contribute to changing the schools' social and/or physical environment, engaging students' families and the local community, and improving resilience.

Trauma research shows that attunement via human contact is central to physiological self-regulation. Relationships are the single most powerful protection against becoming traumatized. After all, "trauma is about loss of connection-to ourselves, to our bodies, to our families, to others, and to the world around us" (Levine, 2005/2008, p. 9). Hence, those who become displaced or exiled - an ever-increasing number of people in Canada, including Indigenous peoples through ongoing colonization, in Canadian schools, and the world-have lost their connection to land, language, culture, and family, and often experience complex trauma. Emotional and interpersonal trauma happens in relationship and so in healing. 
After being in the school four months doing research, I realized that despite genuine concern, many teachers, like regular people, were often disembodied. When present, somatic

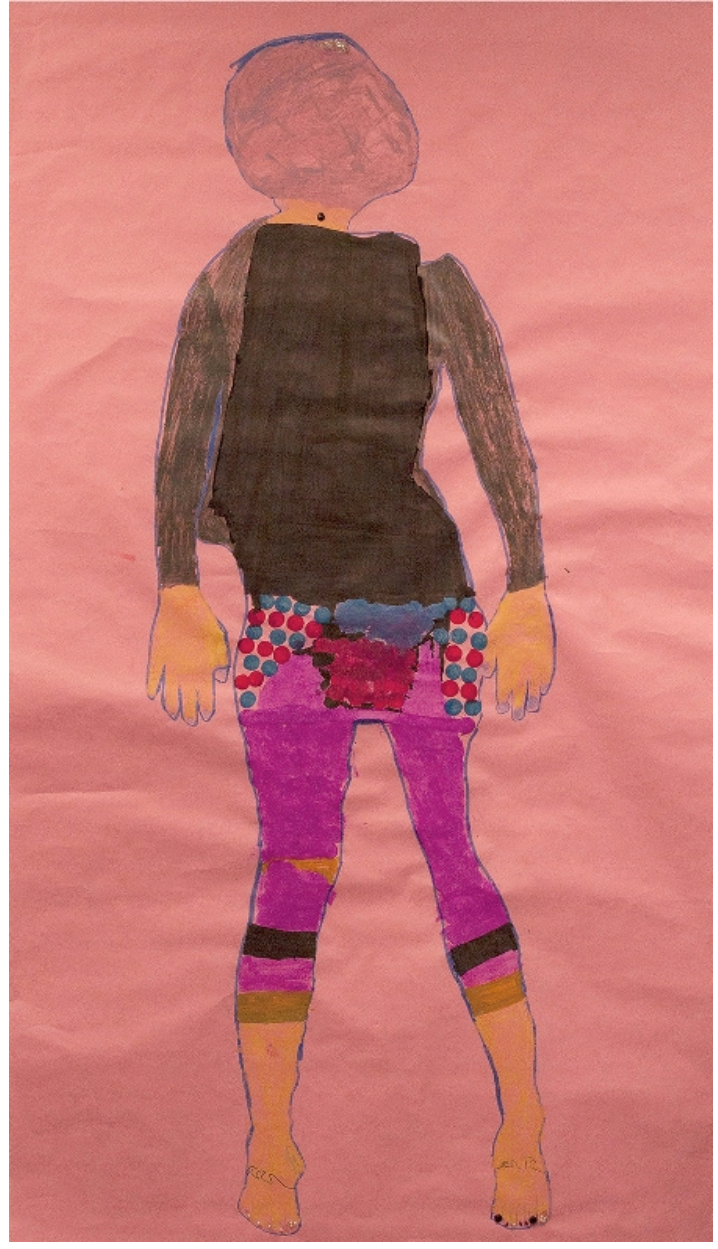

Figure 9. empathy communicates to people that they are seen, felt, and understood just as they are, allowing them to feel felt. When we are not embodied, there can be no somatic resonance, no empathy. I was receptive to the girls' fluctuating and often intense emotions - sadness, anger, worry, and fear-while offering containment and vitality in the moment. Through body language, facial expression, and tone of voice, my nervous system communicated directly with the girls' nervous systems. "In an authentic relationship based on a somatic sense of empathy," describes Stanley (2016), "practitioners are committed to knowing the other in the other's own internal terms" (p. 4). She adds, the "foundation for helping people suffering from trauma lies in the development of an empathetic embodied relationship, a connection that provides the intuitive wisdom to respond to the person in the moment with resonance and contingency" (Stanley, 2016 , p. 5). Somatic empathy does not ask teachers to be mental health professionals; however, it does ask for conscious, embodied relatedness as much as possible. Research in interpersonal neurobiology has uncovered that injuries from trauma lie in the brain and body, not just the mind. We now know what traditional societies have always known: "the brain changes through empathetic relational experiences between individuals within caring communities and, particularly, in the repair of breaches in those relationships" (Stanley, 2016, p. 5).

During the one-on-one interviews at the end of the study, when I asked the girls about their experiences of participating in the project, six of eight deemed the check-ins "their favourite aspect." When asked, "What about them?" They said, "You listened. We got to say how we felt, how we were doing, and we heard about each other." Their pitch and pace changed as they responded. Their faces became quizzical, pensive, perhaps checking to see what I thought of their responses.

The check-ins in hindsight offered them something that was needed in that moment. Listening with presence makes a person feel valued and valuable. Literally, my physical presence was essential. Metaphorically, it meant being emotionally available in a way that the girls felt my undivided attention to them and the needs of the situation moment by moment. This interplay revealed itself again with their second most favourable aspect of the project: me "serving them food and drink." This answer was always sheepishly given. When I probed further, a couple did not know what to say. It became clear; it was not the food alone - it was 
the contact with me via the food. When I reframed the question, "how did it feel when I came to you with a tray of goodies and offered you some?" To this, a few went silent, and a few cried.

In perhaps a maximum two-minute exchange, the girls experienced feeling felt. That is, I was embodied when I made contact; my heart was open to them; I moved slowly, pausing, waiting, giving each lots of time to choose food - to bypass their own reluctance and imposed limitations - and to change their minds. But in that short time span, attunement occurred between our bodies, and they felt it. "Feeling felt" is an embodied physical state akin to Gendlin's (1980) "felt sense" — a bodily awareness of interconnectivity (which includes brainmind) in a given a situation - itself a form of mirroring.

I emphasize "somatic empathy" because empathy has often involved a more cognitive left-hemispheric interpretation - an attempt to understand another without "feeling with" despite empathy meaning "in-feeling." Empathy has been misunderstood as a reflective mental achievement that can occur without full-body participation and awareness of feeling with another (Stanley, 2016). To differentiate, somatic empathy requires a right-brain-to-right-brain relationship (Schore, 2010) - "it is about feeling felt rather than simply being seen, heard, or understood" (Stanley, 2016, p. 105). The right hemisphere of the brain gathers and processes sensory-motor stimulation, primitive emotions, movements, and emergent images (Stanley, 2016, p. 91). Sustained somatic awareness of specific areas in the body accelerates neural firing. Said otherwise, "networks that are actively firing together are wiring together into new neural networks" (Stanley, 2016, p. 91). Networks that become fused in moments of trauma can be separated to fire individually while others can be joined for connectivity. That means, whatever we attend to grows and flourishes neurologically. In this way, the practice of somatic awareness rekindles the energetic life force required for the reorganization of body, brain, and mind. Such vitality, often sheared by trauma, is foremost for "healing and living in the moment in creative, adaptive, and intimate relationships" (Stanley, 2016, p. 91). Vitality is a "manifestation of life, of being alive. We are alert to its feel in ourselves and its expression in others" (Stern, 2010, p. 3). As Stern (2010) elaborates, "We live impressions of vitality like we breathe air" (p. 3), and "we experience people in terms of their vitality" (p. 3) - a felt experience when interacting with others in motion. "The experience of vitality," in his exploration, "is inherent in the act of movement. Movement, and its proprioception, is the primary manifestation of being animate and provides the primary sense of aliveness" (Stanley, 2016, p. 9).

\section{Concluding Remarks}

"Trauma," according to Peter Levine (2005/2008), "is the most avoided, ignored, denied, misunderstood, and untreated cause of human suffering" (p. 7). Its imprints are stored not as narratives about bad things that happened in the past but as palpable sensations that are experienced as real life threats - in the moment. There is much that can be done in our teaching that can support emotional and mental health - integrating movement, pauses and breaks, creative processes, more imagination, breathing techniques, communal activities, meaningful involvement, rituals, sharing circles, and slowing the pace. We can also welcome curiosity, humour, and playfulness - especially play-throughout the day and across all areas of schooling. Most important, both to the girl-participants and trauma research, is emotional regulation through face-to-face contact, taking time to share, and building relationships. The 
structure and implementation of the study included the creation of quiet safe space, fostering safety within the group and among individuals, predictability, clarity of expectations, and consistency. Too, new ways to talk about sensations, the body, and feelings were modeled; attention was given to the transitory nature of feelings; and multiple points of view rather than consensus was encouraged. Indirectly, the study offered the participants ways to practice selfleadership and an internal locus of control. Above all else, we proceeded by the body, with the body, for the body — which always implies brain-mind and soul.

Meeting whole school approaches and select teacher competencies regarding mental health cannot be addressed as a thing to be acquired or to be addressed once and for all. Addressing mental health necessitates fresh understanding alongside the development of relational and somatic skills and attitudes. For without compassion and care, an enduring response to mental health will not be possible. Whether in solitude or with others, our subjective relation to (and relationship with) our own interior informs our capacity to create meaning, connect to sentient beings, and engage life in fulfilling ways. "Our relation to interiority progressively evolves over time and persistently demands that we analyze ourselves in authentically honest and confessional ways, both as we find ourselves in the present and as we wish to be" (Mills, 2017, p. 165).

${ }^{1}$ The Jack Project is Canada's only charity to train and empower young leaders "to revolutionize mental health" across the country. It is a youth-led social movement (see: https://jack.org).

${ }^{2}$ Here, ethical consideration must reflect the values of the paradigm. Meeting the institutional requirements: Research Ethics Board (REB), Cooperative Activities Program for Edmonton's school districts (CAP), which includes a police information check, and the Alberta Teachers Association code of ethics are not enough. These are the formal requirements but alone do not reflect the ethos of the group, the topic, or the axiology of an animated paradigm.

${ }^{3}$ This inclusion was a formal element of the study wherein semi-structured questions were submitted and ethics approval was required.

${ }^{4}$ Feeling is the psychological function that evaluates or judges what something or someone is worth. In Jung's view, it is a rational function, like thinking, in that it is decisively influenced not by perception (as are the functions of sensation and intuition) but by reflection. In his words, "a feeling is as indisputable a reality as the existence of an idea" (CW 16, par. 531).

5 "Humans have a triune brain (three brains functioning together as one mind)" (Levine \& Kline, 2007, p. 86). There are three integral parts that, ideally, work together. The neocortex (new) or rational part of the brain is responsible for inhibition of inappropriate actions, perception, problem solving, planning, and other complex rational thinking skills. The mammalian brain, also known as the limbic system or emotional brain, processes memory and emotion, expresses and mediates instincts and motivational drive, and is connected to attachment. The reptilian or lower brain is responsible for survival - fight, flight, freeze, collapse - and functions that accompany regulatory mechanisms of basic existence (digestion, reproduction, circulation, breathing, etc.). Each part has specialized functions and its own language: the thinking brain speaks with words; the emotional brain speaks with feeling (joy and sorrow); and, the reptilian speaks the unfamiliar but critical language of sensation. When in highly aroused or difficult states, such as fear, access to the rational and relational brains shut down. The autonomic nervous system takes over by registering danger wherein the message becomes: "I must survive." Only when the heightened physiology (trauma) downregulates, do the other brains come on line and so the person can return to relations (emotional), thought (words), and reconnect soul and body in present time. The cycle is complete when a sense of curiosity and interest in the outer world seems to arise naturally (see Levine \& Kline, 2007).

${ }^{6}$ The ATA document, "Creating a Compassionate Classroom," states: "mental illness requires attention from a professional, while mental health problems may simply need support and attention of a caring adult" (p. 3). Such "problems," it explains, "are a common experience of negative or upsetting emotions or thoughts" (p. 3). It is critical to avoid qualifying or judging an emotion, such as anger or fear, as "negative" because its value can only be ascertained in the wider scope of context and consequence. Anger and/or fear- "mammal-universal emotions" (Levine, 2015, p. 22) - might be the very emotion(s) that protect/s the child in a given situation and so the best 
response. In my call for integrative paradigms and perspectives, an argument must be made for intercultural understanding of "mental illness" (see research by Regan Holt, 2019), such as "depression” (ATA, n.d., p. 2). For example, Elders, healers, and communities can tend depression. A similar argument unfolds for diagnosis and treatment by "a medical professional" (p. 2). We stand to gain significant steps in healing cross-culturally if we move out of the singularity and monocracy of an allopathic medical model. There are other valid and valuable conceptions of what constitutes "mental illness" and so its address.

${ }^{7}$ A sympathetic response activates the nervous system wherein access to the pre-frontal cortex is inhibited. The sympathetic response may take the form of fight or flight — mobilizing us to meet the emergency (perceived or real), or its more heightened dorsal vagal reaction, a state of freeze or collapse. A freeze response is accompanied by an intensification of the already activated sympathetic-adrenal arousal, springing us into hyper-drive and simultaneous immobility; we become "scared stiff" (Levine, 2015, p. 45). Once the threat level is perceived as inescapable or mortal, we progress to collapse — "a profound state of hopelessness and helplessness" where our bodies and soul give up and our metabolic processes (digestion, respiration, circulation, and energy production) shut down (p. 45). When stuck in this state of shut down, with both the accelerator and brake fully engaged, the autonomic dynamics may flip back and forth almost instantaneously between sympathetic and parasympathetic (vagal) dominancehyper- and hypo-arousal. When stuck in this unstable phase, people are left in the "sheer hell realm of trauma, paralyzed with terror, while experiencing eruptions of blind rage yet devoid of the sustained energy to act" (p. 46). 8 A parasympathetic response down-regulates the nervous system, permitting access to the mammalian or relational brain.

${ }^{9}$ At the end of the study, after the girls departed from the library, many were seen hours later still carrying their yoga mats slung over their shoulders. Each was gifted her personal yoga mat so that she could "carry the practice" away with her.

10 Without conscious effort here, including an exploration and acknowledgement of one's personal shadow, what is often seen in other is unconscious negative/positive projection of self. In many cases, we are attracted to those who are similar to ourselves (both consciously and unconsciously) and are repelled by those who carry qualities similar to the parts within ourselves that are denied, forgotten, disowned, or disavowed.

${ }^{11}$ These capacities require secure attachment on behalf of the teacher; a well-established and reliable self-awareness; personal knowledge and skills regarding fragmentation, dissociation, and boundaries; shadow work; and emotional regulation. 


\section{References}

Aboriginal Healing Foundation. (2003). Annual Report. Retrieved from http://www.ahf.ca/downloads/annual-report-2003.pdf

Alberta Education. (2017). Working together to support mental health in Alberta schools. Retrieved from https://education.alberta.ca/media/3576206/working_together_to_support_mental_healt h.pdf

Alberta Education. (2018). Teaching quality standards. Retrieved from https://education.alberta.ca/media/3739620/standardsdoc-tqs-_fa-web-2018-01-17.pdf

Alberta Teachers' Association [ATA] (n.d.). Creating a compassionate classroom. Retrieved from https://www.teachers.ab.ca/SiteCollectionDocuments/ATA/Publications/HumanRights-Issues/COOR-79e\%202015\%2012.pdf

Bell Let's Talk. (n.d.) Retrieved from http://letstalk.bell.ca/en/

Brains Beyond Borders. (n.d.) Retrieved from https://www.brainsbeyondborders.ca

Burstow, B. (2005). A Critique of posttraumatic stress disorder and the DSM. Journal of Humanistic Psychology, 45(4), 429-445. doi: 10.1177/0022167805280265

Cajete, G. (2000). Native science. Natural laws of interdependence. Sante Fe: Clear Light Publishers.

Canadian Mental Health Association (CMHA). Retrieved from http:/www.cmha.ca/media/fast-facts-about-mental-illness/\#.WIoRkrYrLZs

Korr, C. (2015) Girls and body image. Retrieved from http://www.commonsensemedia.org/blog/girls-and-body-image-tips

Common Sense Media. (n.d.). 5 Ways to promote a healthy body image for girls. Retrieved from https://www.commonsensemedia.org/blog/girls-and-body-image

De Bellis, M. D. (2010). The neurobiology of child neglect. In R. A. Lanius, E. Vermetten, \& C. Pain (Eds.), The impact of early life trauma on health and disease (pp. 123-132). Cambridge: Cambridge University Press.

Devine, C. (2008). The moon, the stars, and a scar: Body mapping stories of women living with HIV/AIDS. In Border crossings, 58-65. Retrieved from http://www.digitalsinternational.org/cms/content/Carol\%20Devine \%20\%20Body\%20Mapping\%20\%20Border\%20Crossings.pdf

Dove "Girls Self Esteem.” (n.d.). Retrieved from http://www.dove.us/Our-Mission/Girls-SelfEsteem/default.aspx

Duncan, J. S., Duncan, E. K., \& Schofield, G. (2011). Associations between weight perceptions, weight control and body fatness in a multiethnic sample of adolescent girls. Public Health Nutrition, 14, 93-100. doi: 10.1017/S1368980010000236. 
Edmonton Public Schools. (n.d.). Navigating mental health. Retrieved from https:/www.epsb.ca/media/epsb/ourdistrict/topicsofinterest/mentalhealth/NavigatingM entalHealth.pdf

Erickson, K. (1976). Loss of communality at Buffalo Creek. American Journal of Psychiatry, $133,302-305$.

Felitti, V. J. (2010). Foreword. In R. A. Lanius, E. Vermetten, \& C. Pain (Eds.), The impact of early life trauma on health and disease, (pp. xiii-xv). Cambridge: Cambridge University Press.

Felitti, V. J., Anda, R. F., Nordenberg, D., Williamson, D. F., Spitz, A. M., Edwards, V., Koss, M. P., \& Marks, J. S. (1998). Relationship of childhood abuse and household dysfunction to many of the leading causes of death in adults: The Adverse Childhood Experiences (ACE) Study. American Journal of Preventative Medicine, 14(4), 245-355.

Fidyk, A. (2013). Conducting research in an animated world: A case for suffering. [invited] International Journal of Multiple Research Approaches, Special Issue: Depth Psychological Research Approaches, 7(3), 378-391. doi: 10.5172/mra.2013.7.3.384

Fidyk, A. (2017). The influence of cultural and familial complexes in the classroom: A PostJungian View [invited]. In. j. jagodzinski (Ed.). The Precarious future of education: Risk and uncertainty in ecology, curriculum, learning, \& technology, (pp. 71-108). New York: Palgrave Macmillan.

Fidyk, A. (2019). Poetics of the body: Using contemplative, somatic, and arts-integrated methods for well-being. In S. Faulkner \& A. Cloud (Eds.). Poetic inquiry as social justice and political response, (pp. 39-61). Wilmington, DE: Vernon Press.

Fisher, P. A., \& Gunnar, M. (2010). Early life stress as a risk factor for disease in adulthood. In R. A. Lanius, E. Vermetten, \& C. Pain, The impact of early life trauma on health and disease: The hidden epidemic, (pp. 133-147). Cambridge: Cambridge University Press.

Gaywish, R., \& Mordoch, E. (2018). Situating intergenerational trauma in the educational journey. in education, 24(2), 3-23.

Gastaldo, D., Magalhaes, L., Carrasco, C., \& Davy, C. (2012). Body-map storytelling as research: Methodological considerations for telling the stories of undocumented workers through body mapping. Retrieved from http://www.migrationhealth.ca/undocumented-workers-ontario/body-mapping

Gendlin, E. (1980). Focusing. New York: Bantam Books.

Government of Alberta. (2017). Working together to support mental health in Alberta schools. Retrieved from: https://education.alberta.ca/media/3576206/working_together_to_support_mental_healt h.pdf

Government of British Columbia. (2019-2020). Area of learning: Physical and health education. Retrieved from https://curriculum.gov.bc.ca/curriculum/physical-healtheducation 
Government of Ontario. (2015). The Ontario curriculum grades 1-8: Health and physical education (Revised). Retrieved from https://www.oaith.ca/assets/files/2015\%20Health\%20and\%20Physical\%20Education\% 20Curriculum.pdf

Grauwiler, D. (2018, Winter). Mental health: A Changing landscape. ATA Magazine, 99(2), 20-23.

Herman, J. (2015). Trauma and recovery: The aftermath of violence-from domestic abuse to political terror. New York: Basic Books.

Hockley, L. (2018, June). Being in relationship: The ecology of individuation. Paper session presented at the meeting of Jungian Society for Scholarly Studies Conference, Portland State University, Portland, Oregon.

Holt, R. (2019). Exploring intercultural understandings of mental health for school contexts. Unpublished manuscript, Department of Secondary Education, University of Alberta, Edmonton, Canada.

Joint Consortium for School Health (JCSH). (2008). What is comprehensive school health? Retrieved from http://www.jcshcces.ca/upload/JCSH\%20CSH\%20Framework\%20FINAL \%20Nov\%2 008.pdf

Jung, C. G. (1954/1966). "The psychology of the transference" in The Practice of Psychotherapy, The Collected Works of C. G. Jung. (R. F. C. Hull, Trans.), volume 16, (pp. 163-167). Bollingen Series. Princeton, NJ: Princeton University Press.

Kalsched, D. (1996). The inner world of trauma: Archetypal defenses of the personal spirit. Hove: Routledge.

Kalsched, D. (2013). Trauma and the soul: A psycho-spiritual approach to human development and its interruption. Hove: Routledge.

Karlsson, J. (2012). Visual methodologies. In J. Arthur, M. Waring, R. Coe, \& L. Hedges (Eds.). Research methods and methodologies in education (pp. 94-101). Los Angeles, CA: Sage.

Katherine, A. (1991). Boundaries. Center City, MN: Hazelden.

Knowles, J. G., \& Cole, A. L. (Eds.) (2008). Handbook of the arts in qualitative research. Thousand Oaks, CA: Sage Publications.

Kutcher, S., Wei, Y., McLuckie, A., \& Bullock, L. (2013). Educator mental health literacy: A programme evaluation of the teacher training education on the mental health $\&$ high school curriculum guide. Advances in School Mental Health Promotion, 6(2), 83-93.

Lanius, R. A., Vermetten, E., \& Pain, C. (Eds.) (2010). The impact of early life trauma on health and disease: The hidden epidemic. Cambridge: Cambridge University Press.

Leblanc, M., Talbot, P. J., \& Craig, W. M. (2005). Psychosocial health in youth: An international perspective. In M. Ungar (Ed.), Handbook for working with children and 
youth: Pathways to resilience across cultures and contexts (pp. 165-188). Thousand Oaks, CA: Sage Publications.

Levine, P. (2005/2008). Healing trauma: A pioneering program for restoring the wisdom of your body. Boulder, CO: Sounds True.

Levine, P. (2015). Trauma \& memory. Brain and body in a search for the living past. North Atlantic Books: Berkeley, CA.

Levine, P., \& Kline, M. (2007). Trauma through a child's eyes: Awakening the ordinary miracle of healing. Berkeley: North Atlantic Books.

Linklater, R. (2014). Decolonizing trauma work: Indigenous stories and strategies. Halifax and Winnipeg: Fernwood Publishing.

Lombardi, K. L., \& Gordon, A. (2014). Life after "death": An empirical and clinical perspective on trauma. In M. O'Loughlin \& M. Charles (Eds.). Fragments of trauma and the social production of suffering: trauma, history, and memory (pp. 169-184). Lanham, MD: Rowman \& Littlefield Publishers.

Manwell, L. A., Barbic, S. P., Roberts, K., Durisko, Z., Lee, C., Ware, E., \& McKenzie, K. (2015). What is mental health? Evidence towards a new definition from a mixed methods multi-disciplinary international survey. BMJ Open, 5(6), 1-12.

MacGregor, N. H. (2009). Mapping the body: Tracing the personal and the political dimensions of HIV/AIDS in Khayelitsha, South Africa. Anthropology \& Medicine, $16(1), 85-95$.

McCarthy, D. (2007). "If you turned into a monster" Transformation through play: A bodycentred approach to play therapy. London, UK: Jessica Kingsley.

McGilchrist, I. (2009). The Master and his emissary: The Divided brain and the making of the western world. London: Yale University Press.

McHale, K., \& Maidrag, M. (2015, August). Promoting and improving emotional health through building resilience in children and young people using whole school approaches (Version 1.0). Public Health Suffolk. Suffolk County Council. Retrieved from https://www.westsuffolkccg.nhs.uk/wp-content/uploads/2013/01/APPENDIX-5BImproving-Emotional-Health-Building-Resilience.pdf

McNiff, S. (Ed.) (2013). Art as research: Opportunities and challenges. Bristol, UK: Intellect.

McWilliams, N. (2004). Psychoanalytic Psychotherapy: A Practitioner's Guide. New York: Guilford Press.

Mills, J. (2017). Inventing God: Psychology of belief and the rise for secular spirituality. Abingdon, UK: Routledge.

Navaneelan, T. (n.d.). Suicide Rates: An overview. Statistics Canada. Retrieved from https://www150.statcan.gc.ca/n1/pub/82-624-x/2012001/article/11696-eng.htm

Olson, R. (n.d.). Teen Suicide: Is There an Epidemic? Centre for Suicide Prevention. Retrieved 
from https://www.suicideinfo.ca/resource/teensuicide/

Partners for Mental Health (PMH), Canada. Retrieved from http://www.partnersformh.ca

Public Health Agency of Canada (PHAC). The Health of Canada's Young People: A Mental Health Focus. Retrieved from http://www.phac-aspc.gc.ca/hp-ps/dcadea/publications/hbsc-mental-mentale/weight-poids-eng.php

Rosenberg, S. (2017). Accessing the healing power of the vagus nerve. Berkeley: North Atlantic Books.

Rosenberg, J. L., \& Kitaen-Morse, B. (1996). The Intimate couple. Atlanta, GA: Turner Publishing.

Rosenberg, J. L., Rand, M. L., \& Asay, D. (1985). Body, self, \& soul: Sustaining integration. Atlanta, GA: Humanics Trade Group.

Schore, A. N. (2010). The right brain implicit self: A central mechanism of the psychotherapy change process. In J. Petrucelli (Ed.), Knowing, not-knowing and sort of knowing: Psychoanalysis and the experience of uncertainty, (pp. 177-202). London: Karnac.

Schore, A. N. (2012). The science of the art of psychotherapy: The Latest work from a pioneer in the study of the development. New York. W. W. Norton.

Sieff, D. (2015). Understanding and healing emotional trauma: Conversations with pioneering clinicians and researchers. London, UK: Routledge.

Singh Baldwin, S. (1999). What the body remembers. Toronto, ON: Alfred A. Knopf.

Stanley, S. (2016). Relational and body-centered practices for healing trauma: Lifting the burdens of the past. New York: Routledge.

Statistics Canada (2011). Retrieved from https://www12.statcan.gc.ca/nhs-enm/2011/as-sa/99010-x/99-010-x2011001-eng.pdf

Statistics Canada (2012). Retrieved from https://www150.statcan.gc.ca/n1/pub/82-003x/2017001/article/14697-eng.htm

Stern, D. N. (2010). Forms of vitality: Exploring dynamic experience in psychology, the arts, psychotherapy, and development. New York: Oxford University Press.

Stewart, S. L. (2007). "Indigenous mental health: Canadian Native counsellors' narratives." Unpublished doctoral dissertation, University of Victoria, BC.

Unger, M. (2005). Introduction: Resilience across cultures and contexts. In M. Unger (Ed.), Handbook for working with children and youth: Pathways to resilience across cultures and contexts (pp. Xv-Xxxix). Thousand Oakes, CA: Sage Publications.

Unger, M., Brown, M., Liebenberg, L., Othman, R., Kwong, W. M., Armstrong, M., \& Gilgun, J. (2007). Unique pathways to resilience across cultures. Adolescence, (42)166, 287310. 
van der Kolk, B. (2014). The body keeps the score: Brain, mind, and body in the healing of trauma. New York, NY: Penguin Books.

van der Kolk, B., \& d'Andrea, W. (2010). Towards a developmental trauma disorder diagnosis for childhood interperonsal trauma. In R. A. Lanius, E. Vermetten, \& C. Pain, The impact of early life trauma on health and disease: The hidden epidemic, (pp. 57-76). Cambridge: Cambridge University Press.

Wei, Y., Kutcher, S., \& Leblanc, J. C. (2015). Hot idea or hot air: A systemic review of evidence for two widely marketed youth suicide prevention programs and recommendations for implementation. Journal of the Canadian Academy for Child and Adolescent Psychiatry, 24(1), 5-16.

Wei, Y., Kutcher, S., \& Szumilas, M. (2011). Comprehensive school mental health: An integrated "school-based pathway to care" model for Canadian secondary schools. McGill Journal of Education/Revue des sciences de l'education de McGill, 46(2), 213219. doi: 10.7202/1006436ar

Wells, J., Barlow, J., \& Stewart-Brown, S. (2003). A systematic review of universal approaches to mental health promotion in schools. Health Education, 103(4), 197-220. doi: $10.1108 / 09654280310485546$

Westerberg-Jacobson, J., Edlund, B., \& Ghaderi, A. (2010). A 5-year longitudinal study of the relationship between the wish to be thinner, lifestyle behaviours and disturbed eating in 9-20-year old girls. European Eating Disorders Review, 18, 207-219. doi.org/10.1002/erv.983

Wienand, A. (2006). An evaluation of body mapping as a potential HIV/AIDS educational tool. Centre for Social Science Research, working paper 169, 1-32.

Wilson, S. (2008). Research is ceremony: Indigenous research methods. Halifax \& Winnipeg, Fernwood Publishing.

Winnicott, D. W. (1971). Playing and reality. New York: Routledge.

Wirtz, U. (2014). Trauma and beyond: The mystery of transformation. New Orleans: Spring Journal.

Wirtz, U. (2015). Trauma. Paper session presented at the Civilization in translation 5: Historical \& cultural trauma conference. New Mexico: Santa Fe.

Wolynn, M. (2016). It didn't start with you. New York: Viking.

Yehuda, R. (2002). Treating trauma survivors with PTSD. Washington, DC: American Psychiatric Publishing.

World Health Organization [WHO]. Retrieved from http:/www.who.int/features/ factfiles/mental_health/en/ 